\title{
Carbon dioxide removal using kimberlite residues
}

\begin{abstract}
I.M. POWER*, C. PAULO, A.R. STUBBS
Trent School of the Environment, Trent University, Peterborough, Canada (*ianpower@trentu.ca)

The mining of kimberlite for diamonds produces vast quantities of ultramafic residues that may be used to remove carbon dioxide $\left(\mathrm{CO}_{2}\right)$ from the atmosphere [1-3]. In partnership with De Beers Group of Companies, we are investigating kimberlite residues from Voorspoed and Venetia mines in South Africa, and Jwaneng and Orapa mines in Botswana. Kimberlite residues (4.7 Mt of ore treated/yr) from Venetia are a suitable feedstock for $\mathrm{CO}_{2}$ mineralization and enhanced weathering with the capacity to render the mine carbon neutral. Residues have high surface areas, reactive $\mathrm{Mg}$ - and Ca-silicate minerals (e.g., serpentine and diopside), and minimal sulfur and heavy metal content. We have developed a reactivity test for measuring the release of magnesium and calcium from non-carbonate sources and have used mass balance calculations and geochemical modeling to estimate the rate of unintentional $\mathrm{CO}_{2}$ mineralization occurring at the mine today. Carbon sequestration is modest at $2-4 \%$ of the mine's annual emissions $\left(210,000 \mathrm{CO}_{2} \mathrm{e} / \mathrm{yr}\right)$ as $\mathrm{CO}_{2}$ mineralization is limited by the availability of dissolved $\mathrm{Mg}$ and $\mathrm{Ca}$. Strategies that enhance mineral dissolution can be implemented on-site at active and inactive mines or more widely off-site to achieve more significant $\mathrm{CO}_{2}$ sequestration. Acceleration strategies and new carbon verification protocols are being tested in field pilot experiments (m-scale) under real-world conditions. These approaches include the use of $\mathrm{CO}_{2}$ flux chambers to measure the drawdown of atmospheric $\mathrm{CO}_{2}$ directly.

The estimated cost of using existing kimberlite residues for $\mathrm{CO}_{2}$ removal is approximately $\$ 5$ (on-site) to $\$ 25$ (offsite) per tonne of $\mathrm{CO}_{2}$ when considering that mining and comminution have already occurred [4]. In addition to savings under a carbon pricing system, there may be additional cost-benefits from eliminating the need for impoundment closure as mine wastes become a valuable resource for reducing carbon emissions. Large-scale demonstration pilots are needed to further test acceleration strategies and refine $\mathrm{CO}_{2}$ removal rates and cost estimates.
\end{abstract}

[1] Power et al. (2014), Minerals 4, 399-436. [2] Wilson et al. (2011), Environ. Sci. Technol. 45, 7727-7736. [3] Mervine et al., (2018) Miner. Petrol. 112 (Suppl 2), S755S765. [4] Strefler et al. (2018), Environ. Res. Lett. 13, 034010 . 